Bullying

Original article

Paediatrics Today 2013;9(1):112-128

DOI 10.5457/p2005-114.68

\title{
THE ASSOCIATION BETWEEN BULLYING BEHAVIOR, AROUSAL LEVEL, COPING STRATEGIES AND PSYCHOLOGICAL ADJUSTMENT
}

\author{
Kristina SESAR ${ }^{1}$, Nataša SIMIC ${ }^{2}$, Damir SESAR ${ }^{1}$
}

${ }^{1}$ Health Center Siroki Brijeg Bosnia and Herzegovina ${ }^{2}$ Department of Psychology University of Zadar, Croatia ${ }^{1}$ Health Center Siroki Brijeg Bosnia and Herzegovina

\author{
Kristina Sesar \\ Center for Mental Health \\ Health Center \\ Dr. J. Grubišića 11 \\ 88220 Siroki Brijeg \\ Bosnia and Herzegovina \\ kristina.sesar@tel.net.ba \\ Tel.: + 38739703870 \\ Fax.: + 38739704936
}

Received: May 9, 2012

Accepted: December 20, 2012

Copyright (C) 2013 by

University Clinical Center Tuzla.

E-mail for permission to publish: paediatricstoday@ukctuzla.ba
Objective - To examine the relationship between bullying and difficulties in psychological adjustment among elementary school students due to their role in bullying behavior, arousal level and strategies of coping with bullying behavior. Methods - The study was conducted on a convenience sample of 478 primary school children (232 girls and 246 boys), 11 to 15 years of age. A School Relationship Questionnaire (SRQ) was used to assess direct, verbal and relational forms of bullying. To determine the coping strategies we used the Self - Report Coping Measure (SRCM). The arousal level was assessed by The Arousal Predisposition Scale (APS), while Youth Self-Report (YSR) was used for assessing current psychological adjustment. Results - The present study identified $29 \%$ of children involved in bullying; $14 \%$ of children were categorized as victims, $7 \%$ as bullies and $8 \%$ as bully/victims. There was statistically significant combined effect of the role of victims and bully/victims, levels of arousal and coping strategies with bullying (internalizing, externalizing, and distancing) on difficulties in psychological adjustment. Conclusion - Based on the results of this study, we can conclude that bullying as psychosocial stress is an important risk factor for psychological problems in childhood. At the same time, coping strategies are important determinants of successful adaptation.

Key words: Bullying - Difficulties in psychological adjustment Coping strategies - Arousal level

\section{Introduction}

Bullying is not a new phenomenon and has traditionally been considered to be a normal part of childhood or growing up. The common adage "boys will be boys" is an example of 
how aggressive behavior exhibited by male children is minimized or rationalized as somehow natural (1). Social science research has contributed to a shift in public attitudes relating to bullying behavior in schools, and communities are beginning to comprehend the detrimental effects that bullying can have on children. "Bullying" is now widely defined as the "systematic abuse of power" (2), and more specifically as intentional aggressive behavior that is repeated against a victim who cannot readily defend him or herself (3). Besides the traditional roles of bullies, victims, and the noninvolved, a number of studies have examined the situation of bully/victims - children who show characteristics of being both a bully and a victim.

Between $10 \%$ and $30 \%$ of children and youth are involved in bullying. The prevalence of bullying varies significantly as a function of how bullying is measured, with study place and design (4-5). Bullying also increases during the middle school period as children enter adolescence (6). Moreover, bullying is not an isolated problem unique to specific cultures, but is prevalent worldwide, as evidenced by a large international research base (7-10).

Some studies indicate that more boys than girls are affected by bullying (4, 11-14), but the differences are in general small. There are significant differences in the type of bullying between boys and girls. While boys are mostly affected by direct bullying, such as intimidation, abusive acts and direct violent assaults, indirect or relational bullying, such as social isolation, ignoring and spreading of rumors, is more common among girls (15-16).

In the past, bullying was looked upon as a transient and harmless act without serious consequences for those involved (15). Today, however, bullying is found to be associated with psychosocial and somatic illness, especially when the bullying is frequent and long standing (11-12, 17-20). The main focus of research has been on the association between bullying and mental health problems, where level of anxiety, depression, loneliness, self confidence, suicidal behavior and behavioral problems have been found to be associated with bullying $(4,14,20-22)$.

Several studies have also found associations between bullying and somatic symptoms suh as headache, sleep disturbances, stomach pain, enuresis, dizziness, common cold, and musculoskeletal tenderness and pain (17, 23-24). Although the main focus is on the effects on the victims of bullying, attention is also given to the possible social consequences for those who bully others and also to the possible consequences of being involved in bully/victim problems, both as a bully and a victim. Results of different studies suggest that these children are more at risk of developing psychological difficulties than either pure bullies or pure victims (25-26).

Although the concept of coping with stress has been differently defined by authors, coping can generally be conceived as the response to a stressful situation, with the purpose of psychosocial adaptation (27). Strategies of coping with stress include problem-oriented coping and emotion-oriented coping. The former implies attempts by a person to change the stressor, and specific strategies to achieve this change are confrontation and planned problem-solving. As opposed to that, emotion-oriented coping implies attempts to regulate negative emotional responses to a stressor, with self-control and distancing as specific strategies of coping (28). As far as coping behavior in conflictive peer interactions is concerned, studies point out that victims are characterized by internalizing coping strategies, while both bullies and bully/victims show elevated levels of externalizing coping and a lack of problem-solving strategies (29).

Association between abusive experiences and current psychological adjustment is strongly mediated by coping strategies (30). 
Greater use of avoidant coping strategies has been related to greater psychological distress (31). Negative coping strategies may also moderate the links of abusive experiences and psychological adjustment (32). Arousal levels refer to the different states of consciousness associated with different activities (33). Individuals have their own natural arousal level, ranging from low to high, although it varies within each person throughout the day (33). Low levels of arousal have been linked to a number of personality characteristics and behavioral problems. Characteristics of under-aroused individuals include extraversion, impulsiveness, attention problems and conduct problems (34-36). Low arousal also correlates highly with antisocial and criminal behavior in both longitudinal and cross-sectional studies (37).

There is a large void in existing research studies investigating the association between arousal levels, coping strategies, bullying behavior, and psychological adjustment. The results of such investigations could provide an insight into the relationship between bullying and difficulties in psychological adjustment among elementary school students by examining their role in bullying behavior, the level of their arousal and strategies of coping with bullying behavior.

The aim of this study was to examine the association between bullying and difficulties in psychological adjustment among elementary school students, regarding their role in bullying behavior, the level of their arousal and strategies of coping with bullying behavior.

\section{Methods}

\section{Participants}

The research was conducted among 6th and 8th grade students of all the general public schools in the municipality of Siroki Brijeg.
The participants were students at the Elementary School in Siroki Brijeg (335 students), the Kocerin Elementary School (64 students) and the Biograci Elementary School (79 students). One elementary school is located in the urban area, whereas the other two schools are located in the rural area of the municipality. The survey was conducted in November 2009. In the research 536 examinees were included. The processing included only those examinees whose questionnaires were appropriately completed. The sample included results of 478 examinees 232 females $(48.5 \%)$ and 246 males $(51.5 \%)$. The examinees were from 11 to 15 years old (12.73 \pm 1.10 years). The median age was 12 years (interquartile range, 4) (Table 1).

The participants were provided with an information sheet that outlined the main principles of the research and provided contact information if they wished to contact the researchers later on. They were given time to read the information sheet and to ask questions. Completion of the questionnaire was interpreted as consent. Parents had agreed to their participation in a study. The study was approved by Ministry of Science, Education, and Sports of West Herzegovina County, Bosnia and Herzegovina.

\section{Instruments}

We used a sociodemographic questionnaire, School Relationship Questionnaire (SRQ), Youth Self-Report (YSR), The Arousal Predisposition Scale (APS) and Self-Report Coping Measure (SRCM) to collect data on sociodemographics, arousal level, and strategies of coping with bullying behavior. The Youth Self-Report was used to collect data on present psychological adjustment problems. Sociodemographic variables. Sociodemographic variables included students' sex, their age, number of family members and number of children in the family. Involvement in bullying behavior. The exposure to violence among 
Table 1 Demographic characteristics of the participators

\begin{tabular}{|c|c|c|}
\hline \multicolumn{3}{|l|}{ Characteristics } \\
\hline Girls (n; \%) & 232 & 48.5 \\
\hline Boys (n; \%) & 246 & 51.5 \\
\hline Age (years range; $\mathrm{M} \pm \mathrm{SD}$ ) & \multicolumn{2}{|c|}{$11-15 ; 12.73 \pm 1.10$} \\
\hline \multicolumn{3}{|l|}{ Grade } \\
\hline Sixth grade $(\mathrm{n} ; \%)$ & 261 & 54.6 \\
\hline Eighth grade (n; \%) & 217 & 45.4 \\
\hline \multicolumn{3}{|l|}{ Place where research is conducted } \\
\hline Siroki Brijeg (urban area) (n; \%) & 335 & 70.1 \\
\hline Kocerin (rural area) (n; \%) & 63 & 13.2 \\
\hline Biograci (rural area) (n; \%) & 80 & 16.7 \\
\hline \multicolumn{3}{|l|}{ Education of mother } \\
\hline Less than high school diploma (n; \%) & 24 & 5 \\
\hline High school graduate $(\mathrm{n} ; \%)$ & 210 & 43.9 \\
\hline Some college or associate degree ( $\mathrm{n} ; \%)$ & 114 & 23.8 \\
\hline I don’t know (n; \%) & 111 & 23.2 \\
\hline \multicolumn{3}{|l|}{ Education of father } \\
\hline Less than high school diploma (n; \%) & 21 & 4.4 \\
\hline High school graduate $(\mathrm{n} ; \%)$ & 199 & 41.6 \\
\hline Some college or associate degree (n; \%) & 118 & 24.7 \\
\hline I don’t know (n; \%) & 113 & 23.6 \\
\hline The number of family members (Range; $\mathrm{M} \pm \mathrm{SD}$ ) & $3-12$ & \\
\hline The number of children in the family (Range; $\mathrm{M} \pm \mathrm{SD}$ ) & $0-10$ & \\
\hline
\end{tabular}

children was examined using the School Relationship Questionnaire (SRQ) (38). The implementation of the questionnaire in this study was approved by the authors of the questionnaire. For the purpose of this study, the questionnaire was translated into the Croatian language in accordance with the recommended standards for translation of psychological instruments. The questionnaire was translated from English into Croatian and then afterwards a translation was done again from Croatian into English. Due to the fact that the translation contained some minor mistakes, necessary adjustments were made to the Croatian version of the questionnaire.

The questionnaire consists of two parts. In the first part, the examinees evaluate exposure to direct aggressive behavior (Have you had your personal belongings taken?, Have you been threatened or blackmailed?, Have you been hit or beaten up?, Have other things happened to you?) and exposure to verbal-relational aggression by other students (Have other pupils called you nasty names?, Have other pupils not wanted to hang around with you (to make you upset)?, Have other pupils said they wouldn't be friends with you anymore, or said they would tell-tale (tell other people things about you)?, Have other pupils told lies, said nasty things, or told stories about you that were not true?, Have other pupils spoilt activities (for example, sports games or class activities) on purpose (to make you upset)? 
In the second part of the questionnaire, personal aggressive behavior was evaluated (Have you ever taken others personal belongings? Have you threatened/blackmailed someone? Have you hit or beaten someone up? Have you done any other things?) as well as verbal/relational aggression directed to other students (Have you called other pupils nasty names? Have you not hung around with another pupil/other pupils (to make them upset)? Have you told other pupils that you did not want to be friends with them anymore, or said that you would tell-tale (tell other people things about them)? Have you told lies, said nasty things, or told stories about other pupils that were not true? Have you spoilt activities for other pupils (for example, sports games or class activities) on purpose (to make them upset)?)

The answers were assessed on a scale of 1 to 3 , depending on to which extent the respondent was involved in the bullying situation in the last 3 months ("not at all/seldom" = 1 , "often" $=2$ or "very often" = 3). Respondents, who self assessed themselves with 2 or 3 (often or very often) in "Exposure to direct aggressive behavior" part of the questionnaire, were categorized as "direct victims". Respondents who self assessed themselves with 2 or 3 (often and very often) in the "Direct aggression directed towards others" part of the questionnaire were categorized as "direct bullies". Classification of "direct victims" and "direct bullies" (answering 2 or 3, often or very often in both categories in "Exposure to direct aggression" and "Direct aggression directed towards others") resulted in the categorization of bully/victims. All other respondents were categorized as neutral. The same principle was also applied in the classification of "relational victims," "relational bullies," "relational bully/victims" and "neutral".

Arousal level. The Arousal Predisposition Scale (APS) (39) was designed to measure an individual's susceptibility to arousal, viewed as a 'trait', or a predisposition. The APS is a quick and convenient self-report measure of an individual's arousal level, avoiding the need for physiological measurements. Previous studies (39-40) suggest that the APS is a good predictor of individual differences in arousal, and is in concordance with physiological measures of arousal. The APS consists of 12 items and each item is given a score of $1-5$ according to the subject's response $(1=$ never, $2=$ not often, $3=$ occasionally, $4=$ frequently, $5=$ always), excepting the first item, which is scored in reverse. A total arousal score is calculated by summing the scores for each question. The total can range from 12 to 60 , with 12 indicating low levels of arousal and a score of 60 indicating high levels.

As recommended by Coren (40), subjects scoring in the top $10 \%$ ( $\geq 90$ th percentile) and bottom $10 \%$ ( $\leq 10$ th percentile) were categorized as clinically over or under aroused, respectively. The remaining $80 \%(>10 \%,<90 \%)$ were categorized as normal/borderline. If one answer from the questionnaire was missing, the remaining scores were prorated. If more than one answer was absent, the arousal data for that subject was considered missing.

Coping strategies. Modified version of the Self-Report Coping Measure (SRCM) by Causey \& Dubow (28) used to assess coping with five (hypothetical) types of bullying - physical bullying, verbal bullying, indirect bullying, social alienation and intimidation. The SCRM is a 34-item self-report scale consisting of five factor-analytically derived subscales: Seeking Social Support, Self-Reliance/Problem Solving, Distancing, Internalizing and Externalizing. Seeking Social Support, Self-Reliance/Problem Solving, and Distancing are regarded as approach strategies, while Internalizing and Externalizing are regarded as avoidance strategies. In the SRCM, children are asked the questions "When I get a bad grade in school, one worse than I normally get, I usually..." and "When 
I have an argument or a fight with a friend, I usually...." The children answered these questions for each coping strategy item on a fivepoint Likert scale, ranging from "never" (1) to "always" (5). To keep the instrument to a manageable length, when assessing coping with five kinds of bullying, four items from each of the five subscales were selected, making a total of 20 items. The items selected were as follows: for Seeking Social Support, "Get help from a friend", "Ask a family member for advice", "Ask someone who has had this problem what he or she would do", "Talk to the teacher about it"; for Self-Reliance/Problem Solving, "Try to think of different ways to solve it", "Change something so things will work out", "Know there are things I can do to make it better", "Try extra hard to keep this from happening again"; for Distancing, "Make believe nothing happened", "Forget whole thing", "Tell myself it doesn't matter", "Refuse to think about it"; for Internalizing, "Become so upset that I can't talk to anyone", "Worry too much about it", "Cry about it", "Just feel sorry for myself"; and for Externalizing, "Take it out on others because I feel sad or angry", "Yell to let off steam", "Course out loud", "Get mad and throw or hit something". In this modified version of the SRCM, all children were asked the question "Every one of us sometimes hurts other people. We are interested in how you feel and what you do when somebody hurts you (take your personal belongings, threatening you, shock you, call you ugly names or says bad things about you, do not want hang out with you, etc...).“

Psychological adjustment in adolescence. Psychological adjustment in adolescence was assessed with the Youth Self-Report (41), a self-report questionnaire, which consists of two parts, Competencies and Adaptive Scales and Empirically Based-Syndrome and Total Problem Scales. In the present study, we used only the Empirically Based-Syndrome and Total Problem Scales. It is composed of 112 items describing different symptoms or behaviors. Each item is rated on a 3-point Likert scale, ranging from 0 (not true or almost never) to 2 (very true or often true). All ratings refer to symptoms or problems experienced during the preceding 6 months. In the present study, we used only the Empirically Based-Syndrome and Total Problem Scales. The Total Problem scale can be divided into 8 syndrome subscales as follows: "Withdrawn," "Somatic complaints," "Anxious/depressed," "Social problems," "Thought problems," "Attention problems," "Delinquent behavior," and "Aggressive behavior." The subscales "Withdrawn," "Somatic complaints," and "Anxious/depressed" comprise a broad "Internalizing" dimension, whereas "Delinquent" and "Aggressive Behavior" subscales constitute an "Externalizing" dimension. The higher the score on the subscale, the more expressed the trait measured.

\section{Data collection}

Data were collected in November 2009. Students were surveyed at school. After obtaining the consent from the school authorities, the study authors came at the beginning of the period, introduced the study to the students, explained its purpose and encouraged them to participate, pointing out that the survey was anonymous. Afterwards, they were given 45 minutes to fill out the survey during the class period. After completing the questionnaires, they put them in envelopes (which were distributed with questionnaires) and placed them in a collection box located on a desk in the back of the classroom, where students would not feel monitored while depositing them.

\section{Data analysis}

Data were presented as percentages, frequencies, means with standard deviation $( \pm)$ and median (interquartile range). Factor analysis 
with varimax rotation was used to verify the factor structure of the scales. Internal consistency was measured with Cronbach's alpha. Stepwise linear regression analysis was used to calculate multiple correlations between predictor variables (demographic variables, role in bullying behavior, coping strategies, and arousal) and a criterion variable (psychological adjustment). This analysis allows the calculation of the highest possible correlation ( $\mathrm{R}$, multiple correlation coefficients) by optimizing the combination of predictor and criterion variables. The multiple determination coefficient $\left(\mathrm{R}^{2}\right)$ was calculated to show the percentage of criterion variance explained by a set of predictors. $\mathrm{P}<0.05$ was considered statistically significant. Statistical analyses were performed with Statistical Package for Social Sciences v. 17.0 (SPSS Inc, Chicago, IL, USA).

\section{Results}

We obtained responses from 478 students related to the 4 instruments we used. In the factor analysis conducted on all 18 items of the School Relationship Questionnaire, in order to check the factor structure of the questionnaire, with the analysis of basic components with virimax rotation, four factors were extracted - "Direct aggression directed towards others", which explained 15.7\% of the total variance, the second factor "Exposure to direct aggressive behaviour" explained $15.5 \%$ of the total variance, the third factor - "Exposure to verbal/relational aggression" explained $14.5 \%$ of the total variance, and the fourth factor - "Verbal/relational aggression directed towards others" explained $11.9 \%$ of the total variance. In our research, the alpha coefficients obtained for every subscale showed the satisfactory reliability of the type of internal consistency varying from 0.74 to 0.77 . The alpha coefficient for the whole scale was $\alpha=0.88$.
Factor analysis with varimax rotation for the SRCM yielded five factors: Seeking Social Support, Self-Reliance/Problem Solving, Internalizing, Distancing and Externalizing which explained $49.4 \%$ of total variance. The Self-Report Coping Measure subscales showed acceptable reliability in terms of internal consistency. Cronbach's alpha coefficient for the subscales: Self-Reliance/Problem Solving strategies $\alpha=0.63$, Externalizing strategies $\alpha=0.67$, Distancing strategies $\alpha=0.61$, Internalizing strategies $\alpha=0.59$ and Seeking Social Support strategies $\alpha=0.57$. The Cronbach's alpha coefficient for the entire questionnaire was 0.71 .

For the Youth Self-Report (YSR), we used the original factor structure by the author of YSR (41). Subscales showed an acceptable reliability in terms of Cronbach's alpha internal consistency: Withdrawn $\alpha=0.66$, Somatic complaints $\alpha=0.79$, Anxious/Depressed $\alpha=0.81$, Social problems $\alpha=0.73$, Thought problems $\alpha=0.75$, Attention problems $\alpha=0.69$, Delinquent behavior $\alpha=0.80$, Aggressive behavior $\alpha=0.84$, Internalizing dimension $\alpha=0.89$, Externalizing dimension $\alpha=0.90$. The Cronbach's alpha coefficient for the entire scale was $\alpha=0.95$.

In the factor analysis that was conducted for APS to verify the factor structure of the scale, one factor was extracted, and it showed acceptable reliability in terms of Cronbach's alpha internal consistency $(\alpha=0.81)$.

The results of the School Relationship Questionnaire showed that out of 138 (29\%) children involved in bullying behavior 67 (14\%) were categorized as victims, $33(7 \%)$ as bullies, $38(8 \%)$ as bully/victims and $71 \%$ as neutral or children not involved in bullying behavior. The results of the Self-Report Coping Measure (SRCM) revealed that, when confronted with a difficult, stressful, or disturbing situation, participants most frequently used Self-Reliance and Problem Solving strategies, followed by Seeking Social Support strategies, Distancing, Internalizing, and Externalizing (Table 2). 
Table 2 Theoretical score range, and observed score range of responses on the School Relationship Questionnaire, Self-Report Coping Measure, Arousal Predisposition Scale and Youth Self - Report on convenience sample of elementary school children

\begin{tabular}{lllll}
\hline Scale and subscale & Score & & \\
\cline { 2 - 5 } & $\begin{array}{l}\text { Theoretical } \\
\text { range }\end{array}$ & $\begin{array}{l}\text { Observed } \\
\text { range }\end{array}$ & Median & $\begin{array}{c}\text { Quartile } \\
\text { range }\end{array}$ \\
\hline School Relationship Questionnaire & & & & \\
$\quad$ Direct aggression directed toward others & $0-12$ & $0-12$ & 0.00 & 1.00 \\
$\quad$ Verbal/relational aggression directed toward others & $0-15$ & $0-15$ & 1.00 & 2.00 \\
$\quad$ Exposure to direct aggression & $0-12$ & $0-9$ & 0.00 & 1.00 \\
Exposure to verbal/relational aggression & $0-15$ & $0-15$ & 1.00 & 2.00 \\
Self-report Coping Measure & & & & \\
Self-Reliance/Problem Solving & $4-20$ & $4-20$ & 15.00 & 5.00 \\
Externalizing & $4-20$ & $4-19$ & 6.00 & 4.00 \\
Distancing & $4-20$ & $4-20$ & 9.00 & 5.00 \\
Internalizing & $4-20$ & $4-20$ & 7.00 & 5.00 \\
Seeking -Social -Support & $4-20$ & $4-20$ & 10.00 & 5.00 \\
Youth Self-Report & & & & \\
Anxious/depressed & $0-26$ & $0-22$ & 4.00 & 5.00 \\
Withdrawn & $0-16$ & $0-14$ & 2.00 & 3.00 \\
Somatic complaints & $0-20$ & $0-19$ & 3.00 & 4.00 \\
Social problems & $0-22$ & $0-18$ & 3.00 & 4.00 \\
Thought problems & $0-24$ & $0-19$ & 2.00 & 4.00 \\
Attention problems & $0-18$ & $0-17$ & 5.00 & 4.00 \\
Delinquent behaviour & $0-30$ & $0-26$ & 2.00 & 4.00 \\
Aggressive behaviour & $0-34$ & $0-29$ & 5.00 & 7.00 \\
Internalizing dimension & $0-62$ & $0-53$ & 10.00 & 11.00 \\
Externalizing behaviour & $0-64$ & $0-51$ & 7.00 & 9.00 \\
Arousal Predisposition Scale & $12-60$ & $12-56$ & 28.00 & 12.00 \\
\hline
\end{tabular}

The results of the Youth Self-Report (YSR) questionnaire for assessment of psychological adjustment showed that participants most frequently had attention problems, anxiety/ depression, withdrawn, social problems and aggressive behaviors. The frequency of delinquency problems was the lowest. The results of the APS showed that participants mostly had normal arousal levels.

To explore whether sociodemographic variables, arousal levels, coping strategies and roles in bullying behavior predict difficulties in psychological adjustment in elementary school children, we performed a stepwise linear regression analysis to determine the contribution of each variable to explaining the difficulties in psychological adjustment. Scores on the YSR subscales (Anxious/depressed, Withdrawn, Somatic complaints, Social problems, Thought problems, Attention problems, Delinquent behavior, Aggressive behavior, Internalizing dimension, and Externalizing dimension) were taken as criterion variables. Predictive variables were sociodemographic variables (students sex, age, number of family members, number of 
Table 3 Stepwise linear regression, correlation and determination of coefficients for predicting difficulties in psychological adaptation

\begin{tabular}{|c|c|c|c|c|c|}
\hline Predictive variable & $\begin{array}{l}\text { Criterion } \\
\text { variable }\end{array}$ & $\mathrm{R}$ & $\mathrm{R}^{2}$ & Predictors & $\begin{array}{l}\text { Estimate } \\
\text { of } \beta\end{array}$ \\
\hline \multirow{10}{*}{$\begin{array}{l}\text { Sociodemographic } \\
\text { variables (sex, age, number } \\
\text { of family members, number } \\
\text { of children in their family); } \\
\text { roles in bullying behavior } \\
\text { (victim, bully, bully/victim); } \\
\text { coping strategies } \\
\text { (Seeking Social Support, } \\
\text { Self-Reliance/ } \\
\text { Problem Solving, Distancing, } \\
\text { Internalizing and } \\
\text { Externalizing); arousal level. }\end{array}$} & $\begin{array}{l}\text { Anxiety/ } \\
\text { depression }\end{array}$ & 0.619 & 0.376 & $\begin{array}{l}\text { Arousal level } \\
\text { Bully/victim } \\
\text { Internalizing } \\
\text { Victim } \\
\text { Sex }\end{array}$ & $\begin{array}{l}0.315^{* *} \\
0.174 * * \\
0.242^{* *} \\
0.134^{*} \\
-0.079^{*} \\
\end{array}$ \\
\hline & Withdrawal & 0.504 & 0.246 & $\begin{array}{l}\text { Arousal level } \\
\text { Victim } \\
\text { Self-Reliance/Problem solving } \\
\text { Internalizing } \\
\text { Distancing }\end{array}$ & $\begin{array}{l}0.270^{* *} \\
0.189^{* *} \\
-0.178^{* *} \\
0.178^{* *} \\
0.087^{*}\end{array}$ \\
\hline & $\begin{array}{l}\text { Somatic } \\
\text { complaints }\end{array}$ & 0.483 & 0.225 & $\begin{array}{l}\text { Arousal level } \\
\text { Victim } \\
\text { Externalizing } \\
\text { Self-Reliance/Problem Solving } \\
\text { Internalizing }\end{array}$ & $\begin{array}{l}0.282^{* *} \\
0.160 * * \\
0.102 * \\
-0.122^{*} \\
0.120^{*} \\
\end{array}$ \\
\hline & $\begin{array}{l}\text { Social } \\
\text { problems }\end{array}$ & 0.563 & 0.308 & $\begin{array}{l}\text { Victim } \\
\text { Arousal level } \\
\text { Bully/victim } \\
\text { Internalizing } \\
\text { Self-Reliance/Problem Solving } \\
\text { Distancing }\end{array}$ & $\begin{array}{l}0.241^{* *} \\
0.229^{* *} \\
0.142^{*} \\
0.138^{*} \\
-0.126^{*} \\
0.125^{*} \\
\end{array}$ \\
\hline & $\begin{array}{l}\text { Thought } \\
\text { problems }\end{array}$ & 0.544 & 0.284 & $\begin{array}{l}\text { Arousal level } \\
\text { Externalizing } \\
\text { Bully/victim } \\
\text { Sex } \\
\text { Internalizing } \\
\text { Self-Reliance/Problem Solving } \\
\text { Distancing } \\
\text { Victim }\end{array}$ & $\begin{array}{l}0.218^{* *} \\
0.129^{*} \\
0.102^{*} \\
0.126^{*} \\
0.138^{*} \\
-0.119^{*} \\
0.108^{*} \\
0.123^{*}\end{array}$ \\
\hline & $\begin{array}{l}\text { Attention } \\
\text { problems }\end{array}$ & 0.549 & 0.292 & $\begin{array}{l}\text { Arousal level } \\
\text { Externalizing } \\
\text { Bully/victim } \\
\text { Distancing } \\
\text { Internalizing } \\
\text { Self-Reliance/Problem Solving }\end{array}$ & $\begin{array}{l}0.298^{* *} \\
0.128^{*} \\
0.130^{*} \\
0.132^{*} \\
0.142^{*} \\
-0.098^{*}\end{array}$ \\
\hline & $\begin{array}{l}\text { Delinquent } \\
\text { behavior }\end{array}$ & 0.640 & 0.403 & $\begin{array}{l}\text { Externalizing } \\
\text { Sex } \\
\text { Bully/victim } \\
\text { Arousal level } \\
\text { Self-Reliance/Problem Solving } \\
\text { Internalizing }\end{array}$ & $\begin{array}{l}0.361^{* *} \\
0.284^{* *} \\
0.150^{* *} \\
0.123^{*} \\
-0.108^{*} \\
0.095^{*}\end{array}$ \\
\hline & Aggression & 0.639 & 0.400 & $\begin{array}{l}\text { Externalizing } \\
\text { Arousal level } \\
\text { Bully/victim } \\
\text { Sex } \\
\text { Number of family members } \\
\text { Seeking social support }\end{array}$ & $\begin{array}{l}0.406^{* *} \\
0.247^{* *} \\
0.168^{* *} \\
0.101^{*} \\
-0.079^{*} \\
-0.072^{*}\end{array}$ \\
\hline & Internalizing & 0.623 & 0.381 & $\begin{array}{l}\text { Arousal level } \\
\text { Victim } \\
\text { Internalizing } \\
\text { Self-Reliance/Problem Solving } \\
\text { Bully/victim }\end{array}$ & $\begin{array}{l}0.361 * * \\
0.164 * * \\
0.234 * * \\
-0.122^{*} \\
0.120^{*} \\
\end{array}$ \\
\hline & Externalizing & 0.667 & 0.439 & $\begin{array}{l}\text { Externalizing } \\
\text { Bully/victim } \\
\text { Sex } \\
\text { Arousal level } \\
\text { Self-Reliance/Problem Solving }\end{array}$ & $\begin{array}{l}0.421 * * \\
0.166^{* *} \\
0.187 * * \\
0.226 * * \\
-0.083^{*}\end{array}$ \\
\hline
\end{tabular}


children in their family), roles in bullying behavior (victim, bully, bully/victim), different coping strategies (Seeking Social Support, Self-Reliance/Problem Solving, Distancing, Internalizing and Externalizing) as well as score of participants arousal level.

The results showed that arousal level, Internalizing strategies, victim and bully/victim role and gender (girls) explain $38 \%$ of the variance of the criterion variable Anxious/ depressed (Table 3). For Withdrawn as a criterion, the predictive variables explained $25 \%$ of variance. Arousal level, victim role, Self-Reliance/Problems Solving strategies and Internalizing strategies, as well as Distancing strategies were shown as significant predictors of the Withdrawn. Together they explained $25 \%$ of the variance.

The further analysis shows that statistical significance was reached for both Somatic complaints and Social problems. For Somatic complaints, $23 \%$ of the variance was explained by arousal level, Externalizing, Internalizing and Self-Reliance/Problem Solving strategies and victim role in bullying behavior (Table 3).

For Social problems, $31 \%$ of the variance was explained by arousal level, Internalizing, Distancing and Self-Reliance/Problem Solving strategies, and victim and bully/victim roles in bullying behavior.

The predictive variables used explained $28 \%$ of the variance for Thought problems as the criterion. Arousal level, Externalizing, Internalizing and Self-Reliance/Problem Solving strategies, gender (boys) and roles in bullying behavior (bully/victim and victim) were found to be significant predictors. Furthermore, the results showed that arousal level, Externalizing, Distancing, Internalizing and Self-Reliance/ Problem Solving strategies and bully/victims status account for $29 \%$ of the variance of criterion variable Attention problems.

For Delinquent behavior, $40 \%$ of the variance was explained by Externalizing, Self-
Reliance/Problem Solving and Internalizing strategies, gender (boys), and arousal level and bully/victim status. As expected, Externalizing and Seeking Social Support strategies, arousal level, bully/victim status, gender (boys) and number of family members also explain $40 \%$ of the variance of the criterion variable (Aggressive behaviors). Further, for Internalizing dimensions as criterion variables, $38 \%$ of the variance was explained by arousal level, victim and bully/victim status and Internalizing and Self-Reliance/Problems Solving strategies as predictor variables. Finally, the results showed that Externalizing and Self-Reliance/Problem Solving strategies, bully/victim status, gender (boys) and arousal level explain $44 \%$ of the variance of the criterion variable defined as Externalizing dimension.

\section{Discussion}

Our results showed that $138(29 \%)$ of children were involved in bullying behavior and were categorized as follows: $67(14 \%)$ as victims, $33(7 \%)$ as bullies, and $38(8 \%)$ as bully/ victims. The roles of bully/victims and victims are statistically significant predictors of psychological difficulties. Involvement in bullying behavior as bully is not a statistical significant predictor of problems in psychological adjustment. Furthermore, in this research, both Internalizing and Externalizing copying strategies are also statistically significant predictors of psychological difficulties. Self-Reliance/Problem Solving strategies are negatively correlated with psychological difficulties. Based on the above, it can be said that these strategies represent efficient strategies in dealing with bullying behavior. This study also shows that individual levels of arousal are a significant predictor for all the psychological difficulties observed.

The prevalence of bullying behavior in our research was slightly lower than in studi- 
es conducted in Australia, Lithuania, Portugal, Italy and Great Britain (42, 43-46) where up to $54 \%$ of subjects stated that they were involved in bullying behavior. If frequency is to be observed from the point of view of the role in bullying behavior, the result of prior studies show that $7-23 \%$ of subjects are bullies, $5-12 \%$ are victims and $2-21 \%$ are categorized as bully/victims (20, 43, 47-49). The highest prevalence of bullies $(20 \%)$ was found in Denmark, while the highest prevalence of bully/victims (20\%) was found in Lithuania (42). Based on the results of this research, it can be said that there is a higher prevalence of victims, and a lower prevalence of bullies in comparison to prior studies. It is definitely necessary to emphasize that all comparisons to other studies are limited due to their usage of different criteria for determining roles in bullying, different instruments, different times of the year when their research was conducted and different referential periods. The participants of this study who estimated that they were not often exposed to bullying (1 to 3 times since the beginning of the school year) were not identified as victims, bullies, bully/victims, which are not the case in some other studies $(4,50)$.

Based on the results of the research study of Ivarsson et al. (20), we expected that the symptoms of depression and other internalizing psychological difficulties would be more noticeable in girls and externalizing psychological difficulties in boys. However, in this research study, the female sex was shown to be a significant predictor of anxiety/depression, but not for somatic difficulties and withdrawal. As could have been expected, the male sex was shown to be a significant predictor of externalizing psychological difficulties, but also of higher scores on the subscale of thought problems. The observed differences in how the psychological differences manifest themselves in relation to the sex of the participants correspond to the results of previous studies (51) and can be useful to those conducting research or developing interventions targeting specific populations.

The significant correlation between high arousal and internalizing psychological difficulties is also in accordance with the results of other studies $(34-35,38,52)$ in which it was determined that high arousal is clearly related to physical and mental health problems, avoidant behavior, emotional problems, anxiety and inhibition.

Contrary to the results of the majority of previous studies (34-36) in which it was found that low arousal is related to antisocial behavior (behavioral problems, impulsiveness, attention disorders and behavioral problems), we determined a connection between externalizing psychological difficulties and high arousal. However, previous research considered adolescents who were older than those in the current sample (37). The present study also revealed that a large number of subjects in the clinically over-aroused range were bully/victims, which is the bullying profile most at risk of behavior problems $(26,53)$ during childhood and adolescence. Whilst under-arousal is known to be associated with behavior problems, the bully/victim profile, which has been linked to over-arousal, is also associated with behavior problems. In a 14-year longitudinal study, it was found that delinquent individuals with high levels of arousal in adolescence were less likely to persist with antisocial behavior into adulthood than delinquents with low levels of arousal in adolescence (54). In this study, clinical over-arousal was also associated with behavioral problems. Previous research suggests that over-aroused bully/victims will stop having these behavioral problems in adulthood (55), suggesting that this may also be true of our sample.

The literature review did not result in finding any research which would target the 
relationships between violence among children, coping strategies, and psychological adjustment and, therefore, it is not possible to make a direct comparison of the obtained results. As a result of this, our attention will be directed to previous research studies which examined coping strategies and psychological difficulties.

Based on the conducted regression analyses, we determined that Internalizing coping strategies are statistically significant predictors of internalizing and externalizing psychological difficulties, as well as social problems and thought problems. Externalizing as a strategy for coping with bullying behavior is also a statistically significant predictor for externalizing psychological difficulties, thought problems, and attention problems. It has to be stated that both Internalizing and Externalizing, as strategies, represent avoidance strategies. Therefore, their predictable contribution to the explanation of the variance of these difficulties is expected. The above stated is supported by results of previous research. For example, the chronic usage of some coping strategies in adolescents, avoidance strategy in particular, represents a risk factor, which contributes to development of negative symptoms related to the effect of a stressful event (56). Folkman and Lazarus (57) also state that avoidance has a short term adaptive effect and that it most commonly has long term emotional consequences. In the research conducted by Kardum and Hudek-Knežević (58), avoidance was a significant predictor of negative mood in the observed student sample. A connection between avoidance and negative psychological difficulties was also confirmed in the research study of Sults and Fletcher (59). However, these authors state that negative effects of avoidance are only exhibited when delayed outcomes of coping are observed, while the use of avoidance within short time periods often leads to better adjustment and favorable effects on health.
The results of this study are in accordance with the results of previous studies (57, $60)$ and they show that subjects who use SelfReliance and Problem Solving strategies less have more internalizing and externalizing psychological difficulties. Planned problem solving is significantly related to emotional state (more positive and less negative emotions) for at least two reasons (57). Firstly, people feel better because of the mere fact that they are solving the problem which is causing the stress. Secondly, efficiently planned problem solving can improve the relationship between an individual and their surroundings, which leads to better cognitive evaluation and positive emotional responses (57).

The results of previous research $(4,42$, 61) indicate that children who are a target of bullying behavior as victims and bully/victims are at significantly higher risk for a variety of psychological problems, when compared to uninvolved peers. Similarities between victims and bully/victims in several domains, such as low emotional adjustment and poor relationships with classmates, are commonly found in large survey studies across the world $(42,62)$. Bullies were also found to be at significantly higher risk for externalizing disorders, anxiety and somatic complains than uninvolved peers $(2,20,61)$. In this resear$\mathrm{ch}$, the largest effect sizes were for victims and bully/victims, whereas no connection between bullies and psychological difficulties was confirmed. This result confirms the fact that, among all children involved in the bullying phenomenon, the highest numbers of adjustment problems are manifested by victims and bully/victims (4, 42, 61, 63-64).

The connection between involvement in bullying behavior and psychological difficulties becomes clearer when the stressful nature of victimization is examined. The transactional stress model suggested by Cox (65) considers that stress is created when a person experiences a significant imbalance between 
the demands placed on him or her and his or her perception of how to face them (imbalance). When this is reviewed in the context of peer aggression, the following characteristics are present: 1) the demands placed on a person are greater than a person's ability to handle them ; 2) the victimized person is in a situation where his or her escape is difficult or impossible and he or she uses different strategies which are insufficient (for example, asking for help, avoiding confrontation, etc.); 3) the person isolates himself/herself and avoids interaction with others; 4) the victim perceives the situation as out of control and it is estimated that the victimization will last (2). Such experiences can change the emotional state of a person and result in an increased level of anxiety and depression, as well as in changes in different physiological functions (65). The above mentioned experiences can lead to weakened immunity in some persons, including susceptibility to different infections and other health problems (66).

It can be concluded that psychosocial stress such as bullying represents a very important risk factor for psychopathological disorders in childhood and adolescence, and therefore coping is an important determinant of successful adaptation (67-68).

A self-evaluation questionnaire was used in this research to estimate the involvement of children in bullying behavior, as well as for observation of other variables. We are aware of the fact that self-evaluation questionnaires are not as reliable as diagnostic interviews. However, the use of questionnaires and evaluation scales allows researchers to conduct research with larger numbers of subjects. Moreover, evaluation of student involvement in bullying behavior using questionnaires might be difficult particularly for identifying those students who bully, but are not aware of their negative behavior towards other students, or those who refuse to admit their active role in bulling. Although self-eva- luations are a common and accepted method for evaluation of bullying, individual perception of violence might vary. To minimize the bias in this research, students were provided definitions of bulling with examples.

One of the limitations of this research is that the students were the only source of information on the involvement in bullying and difficulties in psychological adjustment. Future studies should include multiple sources of information (parents, teachers, other children, etc.) both in determining roles in bullying behavior and in evaluation of psychological difficulties, i.e. student observations to ensure greater reliability of answers.

Finally, it is also necessary to review some methodological difficulties in analyzing obtained data on coping strategies. These results are also based on self-evaluation of children, although we should mention that Causey and Dubow (28) determined that the evaluation of other students correlated quite well to the selfevaluation obtained using SRCM. In this research, as is generally done in other studies on coping, children were asked to answer how they would react if they were exposed to bullying.

It is assumed that children who experienced different forms of bullying would answer questions identifying the coping strategies they used in the situations when they were exposed to abuse. However, theoretically, if a child exposed to bullying uses strategies which do not reduce violence, it is possible that he/she might contemplate different ways of responding to abuse, which would include more efficient methods. Therefore, student responses might reflect the use of wished-for strategies, and not necessary the strategies they used in the present situation.

Furthermore, the obtained results in this research significantly contribute to the examination of the relationship between bullying and arousal. Namely, bullying is one aspect of antisocial behavior which has not been explored so far in the context of its 
connection to individual levels of arousal. Newer studies (69) suggest that the connection between the level of cortisol and antisocial behavior might vary, depending on types of antisocial behavior, forms of comorbidity and early unfavorable surrounding events. Therefore, future studies should examine the relationships between arousal and different forms of antisocial behavior.

Besides that, the influence of genetic inheritance, as well as the environment should be taken into consideration when explaining the connection between arousal and aggressive behavior. Some researchers (70) emphasize that individuals have a genetic predisposition for certain levels of arousal and aggressive behavior, and the influence of their envi-

\section{References}

1. Craig WM. The relationship among bullying, victimization, depression, anxiety, and aggression in elementary school children. Pers Individ Dif. 1998;24:123-30.

2. Rigby K. New perspectives on bullying. London and Philadelphia: Jessica Kingsley Publishers; 2002.

3. Olweus D. Bullying at school: What we know and what we can do [in Croatian]. Zagreb: Školska knjiga; 1998.

4. Nansel TR, Overpeck MD, Pilla RS, Ruan WJ, Simons-Morton B, Scheidt P. Bullying behaviors among US youth: prevalence and association with psychosocial adjustment. JAMA. 2001;285:2094-100.

5. Solberg ME, Olweus D. Prevalence estimation of school bullying with the Olweus Bully/Victim Questionnaire. Aggressive Behav. 2003;29:239-68.

6. Rios-Ellis B, Bellamy L, Shoji J. An examination of specific types of ijime and their prevalence within Japanese schools. School Psychol Int. 2000; 21(3):227-41.

7. Carney AG, Merrell KW. Perspectives on understanding and preventing an international problem. School Psychol Int. 2001;22:364-82.

8. Cook CR., Williams KR., Guerra N, Kim T. Variability in the prevalence of bullying and victi- ronment contributes to the manifestation of certain forms of behavior. Only lately have researchers started examining possible genetic influences (temperament, physiological responses etc.) and their interaction with the environmental effects (parental discipline, student delinquency) in developing aggressive forms of behavior (71).

Authors' contributions: Conception and design: KS, NŠ; Acquisition, analysis and interpretation of data: KS, DS, NŠ; Drafting the article: KS, DS; Revising it critically for important intellectual content: KS, NŠ, DS.

Conflict of interest: The authors declare that they have no conflict of interest. This article was not sponsored by any external organization.

mization: A cross-national and methodological analysis. In:, Jimerson SR, SM, Swearer SM, Espelage DL, editors. The international handbook of school bullying. Mahwah, NJ: Erlbaum; 2009. p. 347-362.

9. Eslea M, Menesini E, Morita Y, O’Moore M, MoraMerchan JA, Pereira B, et al. Friendship and loneliness among bullies and victims: Data from seven countries. Aggressive Behav. 2004;30(1):71-83.

10. Kanetsuna T, Smith PK. Pupil insights into bullying, and coping with bullying: A bi-national study in Japan and England. J School Violence. 2002;1:5-29.

11. Due P, Holstein BE, Lynch J, Diderichsen F, Gabhain SN, Scheidt P, Currie C. Bullying and symptoms among school-aged children: international comparative cross sectional study in 28 countries. Eur J Public Health. 2005;15(2):128-32.

12. Hanish LD, Guerra NG. A longitudinal analysis of patterns of adjustment following peer victimization. Dev Psychopathol. 2002;14(1):69-89.

13. Nishina A, Juvonen J, Witkow MR. Sticks and stones may break my bones, but names will make me feel sick: the psychosocial, somatic, and scholastic consequences of peer harassment. J Clin Child Adolesc Psychol. 2005;34(1):37-48. 
14. Solberg ME, Olweus D, Endresen IM: Bullies and victims at school: are they the same pupils? $\mathrm{Br} \mathrm{J}$ Educ Psychol. 2007;77(Pt 2):441-64.

15. Storch EA, Ledley DR. Peer victimization and psychosocial adjustment in children: current knowledge and future directions. Clin Pediatr (Phila). 2005;44(1):29-38.

16. Wal MF van der, de Wit CA, Hirasing RA. Psychosocial health among young victims and offenders of direct and indirect bullying. Pediatrics. 2003;111(6 Pt 1):1312-7.

17. Fekkes M, Pijpers FI, Verloove-Vanhorick SP: Bullying behavior and associations with psychosomatic complaints and depression in victims. J Pediatr. 2004;144(1):17-22.

18. Kim YS, Koh YJ, Leventhal B. School bullying and suicidal risk in Korean middle school students. Pediatrics. 2005;115(2):357-63.

19. Lataster T, van OJ, Drukker M, Henquet C, Feron F, Gunther N, Myin-Germeys I. Childhood victimisation and developmental expression of non-clinical delusional ideation and hallucinatory experiences: victimisation and non-clinical psychotic experiences. Soc Psychiatry Psychiatr Epidemiol. 2006;41(6):423-8.

20. Ivarsson T, Bronberg AG, Arvidsson T, Gillberg C. Bullying in adolescence: Psychiatric problems in victims and bullies as measured by Youth Self Report (YSR) and the Depression Self-Rating Scale (DSRS). Nord J Psychiatry. 2005;59:36573.

21. Liang H, Flisher AJ, Lombard C. Bullying, violence, and risk behavior in South African school students. Child Abuse Negl. 2007;31(2):161-71.

22. Storch EA, Masia-Warner C. The relationship of peer victimization to social anxiety and loneliness in adolescent females. J Adolesc. 2004;27(3):351-62.

23. Sesar D, Sesar K. Psychosomatic problems as the resault of participation in bullying behavior or risk factor for involvment in bullying behavior? Paediatrics Today. 2012;8(2):114-26.

24. Wolke D, Woods S, Bloomfield L, Karstadt L.Bullying involvement in primary school and common health problems. Arch Dis Child. 2001;85(3):197-201.

25. Duncan R. Maltreatment by parents and peers: The relationship between child abuse, bully vic- timization, and psychological distress. Child Maltreat. 1999;19:45-56.

26. Wolke D, Woods S, Bloomfield L, Karstadt L.The association between direct and relational bullying and behaviour problems among primary school children. J Child Psychol Psychiatry. 2000;41:989-1002.

27. McCrae RR. Situational determinants of coping responses: Loss, threat, and challenge. J Pers Soc Psychol. 1984;46:919-28.

28. Causey LD, Dubow FE. Development of a SelfReport Coping Measure for Elementary School Children. J Clin Child Psychol. 1992;21(1):47-59.

29. Bijttebier P, Vertommen, H. Coping with peer arguments in school-age children with bully/victim problems. Br J Educ Psychol. 1998;68:387-94.

30. Runtz M, Schallow JR. Social support and coping strategies as mediators of adult adjustment following childhood maltreatment. Child Abuse Negl. 1997;2:211-26.

31. Min M, Farkas K, Minnes S, Singer LT. Impact of childhood abuse and neglect on substance abuse and psychological distress in adulthood. J Trauma Stress. 2007;20:833-44.

32. Huang G, Zhang Y, Momartin S, Huang X, Zhao L. Child sexual abuse, coping strategies and lifetime posttraumatic stress disorder among female inmates. Int Journal Prison Health. 2008;4(1):54-63.

33. Eysenck HJ, Gudjonsson GH. The causes and cures of criminality. New York: Plenum Press; 1989.

34. Eysenck H. Crime and Personality. London: Routledge and Kegan Paul; 1964.

35. Knyazev GG, Slobodskaya HR, Wilson GD. Psychophisical correlates of behavioural inhibition and activation. Pers Individ Dif. 2002;33:647-60.

36. Matthews G, Deary IJ. Personality traits. Cambridge: Cambridge University Press;1998.

37. Raine A, Venables PH, Williams M. Relationships between central and autonomic measures of arousal at age 15 years and criminality at age 24 years. Arch Gen Psychiatry. 1990;47(11):1003-7.

38. Woods S, White E. The association between bullying behaviour, arousal levels and behaviour problems. J Adolescence. 2005;28:381-95.

39. Coren S. Prediction of insomnia from arousal predisposition scores: Scale development and cross - validation. Behav Res Ther. 1988;26(5):415-20. 
40. Coren S, Mah KB. Prediction of physiological arousablity: A validation of the Arousal Predisposition Scale. Behav ResTher. 1993;31:215-9.

41. Achenbach TM. Manual for the Youth Self-Report and 1991 Profile. Burlington, VT: University of Vermont Department of Psychiatry; 1991.

42. Nansel TR, Craig, W, Overpeck MD, Saluja G, Ruan WJ. Health Behaviour in School-aged Children Bullying Analyses Working Group. Crossnational Consistency in Realtionship Between Bullying Behaviours and Psychosocial Adjustment. Arch Pediatr Adolesc Med. 2004;158:730-6.

43. Forero R, McLellan L, Rissel C, Bauman A. Bullying behaviour and psychological health among school students in new South Wales, Australia: Cross sectional survey. BMJ. 1999; 319 (7206):344-8.

44. Whitney I, Smith PK. A survey of the nature and extent of bully/victim problems in junior/middle and secondary schools. Educ Res. 1993;35:3-25.

45. Fonzi A, Genta ML, Menesini E, Bacchini D, Bonino S, Costabile A. 'Italy'. In: Smith PK, Morita Y, Junger Tas J, Olweus D, Catalano R. Slee P, editors. The nature of school bullying: A CrossNational Perspective. London and New York: Routledge; 1999. p. 140-56.

46. Pereira B, Mendonca D, Neto C, Valente L, Smith PK. Bullying in Portuguese Schools'. School Psychol Int. 2004;25(2):241-54.

47. Juvonen J, Graham S, Schuster MA. (2003). Bullying among young adolescents: the strong, the week, and the troubled. Pediatrics. 2003;112:1231-7.

48. Mazur J, Malkowska A. Bullies and victims among Polish school-aged children. Medycyna Wieku Rozwojowego. 2003;7:121-34.

49. Yang SJ, Kim JM, Kim SW, Shin IS, Yoon JS. Bullying and victimization in boys and girls at South Korean primary schools. J Am Acad Child Adolesc Psychiatry. 2006;45(1):69-77.

50. Arseneault L,Walsh E, Kali Trzesniewski K. Bullying victimization uniquely contributes to adjustment problems in young children: a nationally representative cohort study. Pediatrics. 2006;118:130-8.

51. Leadbeather BJ, Kuperminc GP, Blatt SJ, Hertzog CA. Multivariate model of gender differences in adolescentts internalizing and externalizing problems. Dev Psychol. 1999;35(5):1268-82.
52. Strelau J. Temperament: A psychological perspective: New York NY: Plenum; 1998

53. Kumpulainen K, Räsänen E. Children involved in bullying at elementary school age: Their psychiatric symptoms and deviance in adolescence. An epidemiological sample. Child Abuse Negl. 2000;24:1567-77.

54. Raine A, Venables PH, Williams M. High autonomic arousal and electrodermal orienting at age 15 years as possible protective factors against criminal behavior at age 29 years. Am J Psychiatry. 1995;152:1595-600.

55. Connor DF. Aggression \& antisocial behaviour in children and adolescents: research and treatment. London: The Guildford Press; 2002.

56. Aspinwall LG, Taylor SE. Modeling cognitive adaptation: A longitudinal investigation of the impact of individual differences and coping on college adjustment and performance. J Pers Soc Psychol. 1992;63:989-1003.

57. Folkman S, Lazarus RS. Coping and emotion. In: N. L. Stein, B. Leventhal, T. Trabasso (ur.), Psychological and biological approaches to emotion., Hillsdale:, Lawrence Erlbaum Associates; 1990 p. 313-332.

58. Kardum I, Hudek-Knežević J. The relationship between Eysenck's personality traits, coping styles and mood [in Croatian]. Godišnjak Odsjeka za psihologiju. 1994;3:97-106.

59. Suls J, Fletcher B. The relative efficacy of avoidant and nonavoidant coping strategies: A metaanalysis. Health Psychol. 1985;4:249-88.

60. Billings DW, Folkman S, Acree M. Tedlie Moskowitz J. Coping and physical health during caregiving: The roles of positive and negative affect. J Pers Soc Psychol. 2000;7:131-42.

61. Hampel P, Dickow B, Hayer T, Petermann F. Coping, adjustment, and bullying among male children and adolescents. Prax Kinderpsychol Kinderpsychiatr. 2009;58(2):125-38.

62. Gini G, Pozzoli T. Association Between Bullying and Psychosomatic Problems: A Meta-analysis. Pediatrics. 2009;3:1059-65.

63. Hanish LD, Guerra NG. Aggressive victims, passive victims, and bullies: Developmental continuity or developmental change? Merrill Palmer Quart. 2004;50:17-38. 
64. Schwartz D, Proctor LJ. Community violence exposure and children's social adjustment in the school peer group: the mediating roles of emotion regulation and social cognition. J Consult Clin Psychol. 2000;68:670-83.

65. Cox T. Stress, coping and physical health. In: Broome A, Llewelyn S, editors.Health Psychology: Process and Applications. Second Edition. London: Singular Publication Group; 1995.

66. Vaernes RJ, Myhre GA, Henrik H, Homnes T. Relationships between stress, psychological factors and immune levels among military aviators. Work Stress. 1991;5:5-16.

67. Rybski B. The role of emotion in children`s selection of strategies for coping with daily stresses. Merrill Palmer Quart. 1997;43:129-46.
68. Compas BE, Connor-Smith JK, Saltzman H, Harding Thomsen A, Wadsworth ME. Coping with stress during childhood and adolescence: Problems, progress, and potential theory and research. Psychol Bull. 2001;127:87-127.

69. Hawes DJ, Brennan J, Dadds MR. Cortisol, Callous-unemotional Traits, and Pathways to Antisocial Behavior. Curr Opin Psychiatr. 2009;22(4):357-62.

70. DiLalla LF. Behaviour genetics of aggression in children: review and future directions. Dev Rev. 2002;22:593-622.

71. Plomin R, Owen MJ, McGuffin P. The genetic basis of complex human behaviors. Science. 1994;264:1733-9.

Citation: Sesar K, Simic N, Sesar D. The association between bullying behavior, arousal level, coping strategies and psychological adjustment. Paediatrics Today. 2013;9(1):112-28. 